\title{
LA HISTORIA REGIONAL EN LA ARGENTINA. SUS APORTES Y DESAFÍOS PARA EL FUTURO
}

\author{
María del Mar Solís Carnicer"
}

La historia regional ha tenido un enorme desarrollo en las últimas décadas. A los importantes aportes en el área de la historiografía mexicana o brasilera, se han sumado trabajos en Venezuela, Colombia, Chile y otros países de América Latina. La Argentina también ha avanzado en esa dirección a partir de las investigaciones de historiadores e historiadoras de las diferentes regiones y provincias. La tradicional Historia Nacional de corte centralista concebida a fines del siglo XIX y desarrollada a lo largo de todo el siglo XX -según la cual la Historia de Buenos Aires o rioplatense podía considerarse como sinónimo de Historia Argentina- ha sido fuertemente cuestionada y discutida en los últimos años. Las numerosas contribuciones realizadas por la historiografía regional han sido fundamentales en ese campo.

La progresiva formación de los historiadores provinciales a través de una carrera universitaria, permitió la definición de un campo profesional en el ámbito de las provincias. De esta manera, los estudios regionales comenzaron a extenderse a raíz de la expansión de las universidades y centros de investigación A esta renovación de la historia regional han contribuido diferentes disciplinas sociales como la economía, la demografía, la sociología, la antropología, la teoría literaria, los estudios culturales y las ciencias políticas. Por otra parte, este desarrollo también se vio favorecido con el mejoramiento de los archivos locales, las políticas estatales de descentralización de los centros de educación superior, el intercambio académico de los historiadores en congresos y reuniones y los proyectos colectivos de investigación multidisciplinar. La sistematización de estos trabajos no sólo ha permitido ampliar el conocimiento sobre un vasto campo sino, en especial, ha abierto la puerta a nuevas perspectivas metodológicas de trabajo. Al mismo tiempo que se ha avanzado en el conocimiento de los procesos políticos, económicos y sociales, se ha reflexionado acerca de la relación entre la historia nacional y la historia regional o provincial y sobre la pertinencia de estos estudios y

\footnotetext{
* Directora de la Especialización en Historia Regional de la Facultad de Humanidades - UNNE, Prof. Titular por concurso en la cátedra Historia Argentina Contemporánea de la misma Facultad e Investigadora Adjunta de Conicet en el IIGHI (Conicet- UNNE)
} 
el carácter que debe asumir la historia regional. En definitiva, la historia argentina se volvió más compleja, más interesante, más llena de variedades y de matices.

Sin embargo, y a pesar de la enorme producción renovada, debe señalarse que en esta historia regional más reciente, aún subsisten enfoques tradicionales, donde el objeto de las investigaciones se reduce a la promoción de los héroes locales o a escribir la historia de "sus" pueblos, municipios, regiones o provincias, sin buscar ampliar la mirada más allá de esos límites cercanos. Muchas veces la historia regional se aisló de la historia en general, reduciéndose a una historia local - o más aún, localista- que la aleja de la posibilidad de dar respuesta a problemas generales. Por ello es que la historia regional, puede ser un muy buen complemento a las tendencias globalizadoras actuales, pero sólo si tiene en cuenta la existencia de estos debates e interpretaciones y se presenta como una forma concreta de percibir esa globalidad. En este sentido consideramos que uno de los principales aportes que puede brindar el estudio de la historia regional es su contribución a la mejora del entendimiento de la relación entre lo particular y lo general, de lo micro con lo macro, del sujeto con la estructura. Abordada desde esta perspectiva, la historia regional puede conducir a modificaciones sobre modelos consolidados y por tanto, plantear nuevos interrogantes o encontrar nuevas respuestas a viejas problemáticas.

En este caso reunimos en el presente dossier tres contribuciones de importantes historiadoras especializadas en la historia regional. Las mismas fueron originalmente expuestas en forma de conferencias en el marco de la Especialización en Historia Regional de la Facultad de Humanidades de la Universidad Nacional del Nordeste entre 2013 y 2015 ${ }^{1}$. Se trata de los aportes de María Silvia Leoni (UNNE) ${ }^{2}$, Susana Bandieri (UNCo- Conicet) ${ }^{3}$ y Sandra Fernández (UNR- Conicet) ${ }^{4}$. Decidimos reunirlas y publicarlas porque consideramos que las reflexiones y aportes que cada una de ellas realizan, son fundamentales para entender qué es, para qué sirve y cómo se hace historia regional. Al tiempo que señalan los problemas y desafíos que se plantean hacia el futuro ${ }^{5}$.

María Silvia Leoni, en su artículo "Historia y Región: La Historia Regional de cara al siglo XXI", se pregunta sobre los conceptos de región, regionalismo y regionalización, establece una diferenciación entre los mismos y señala las confusiones más comunes que se dan en su uso. Se interesa también por analizar el proceso de construcción de la región en la Argentina trazando un paralelismo con la construcción

${ }_{1}$ La Especialización en Historia Regional es una carrera de posgrado que se dicta en la Facultad de Humanidades de la Universidad Nacional del Nordeste en la ciudad de Resistencia (Chaco- Argentina) desde el año 2013. Actualmente se encuentra en curso la segunda cohorte. http://hum.unne.edu.ar/ postgrado/especializ_historia/especializ_historia.htm

2 María Silvia Leoni dictó la conferencia inaugural de la primera cohorte de la carrera el 17 de mayo de 2013.

3 Susana Bandieri dictó su conferencia el 6 de diciembre de 2013.

4 Sandra Fernández dictó la conferencia inaugural de la segunda cohorte de la carrera el de 2 de octubre de 2015.

5 Estas mismas conferencias -junto a la de otros investigadores- se encuentran disponibles en el canal de youtube de la Especialización en Historia Regional de la Facultad de Humanidades de la UNNE URL: https://www.youtube.com/user/EspecializacionUNNE 
del estado nacional. Luego avanza específicamente sobre la historia regional, sus características y prácticas en América latina y Argentina y los aportes de la misma en los últimos años. Finalmente, dedica un espacio a la reflexión sobre la relación entre la historia regional y la educación, en el que señala el cada vez mayor interés por incluir en la escuela la enseñanza de la historia regional y los problemas y desafíos que ello planteó al sistema educativo argentino.

En "La Patagonia en clave regional: un camino posible para una historiografía renovada", Susana Bandieri se concentra fundamentalmente en la forma en la que fue concebida tradicionalmente la historia argentina y el modo en que ésta abordó a las regiones, fundamentalmente la Patagonia. Señala los problemas de periodización que se plantean en la historia argentina tradicional que no tuvo en cuenta los procesos diferenciados en cada una de las regiones. A partir de la historia de la Patagonia plantea las posibilidades que la historia regional ofrece para enriquecer y renovar la historiografía argentina sobre todo aquella "demasiado generalizante y encerrada en los límites territoriales del Estado- Nación”.

Por último, Sandra Fernández, en su artículo "La perspectiva regional/local en la historiografía social argentina" analiza críticamente su desarrollo en las últimas décadas deteniéndose especialmente en aquellos hitos que hicieron posible su consolidación y proyección. Reflexiona acerca de las influencias recibidas desde diferentes latitudes y tradiciones y se cuestiona acerca de sus limitaciones y posibilidades. En este agudo examen identifica aquellos ejes que distinguen a este tipo de estudios: sus estrechos vínculos con la historia social y la relevancia de la dimensión contextual como principio de organización de la investigación.

Los tres artículos - desde sus propias perspectivas y propósitos- muestran con claridad el importante recorrido que ha realizado la historia regional en la historiografía argentina así como también señalan aspectos por mejorar y caminos que todavía quedan por transitar hacia el futuro. Las tres autoras coinciden en que la reflexión teóricometodológica por parte de quienes trabajan en ella resulta fundamental si lo que se busca es hacer una historia más rica y más compleja. Este dossier fue pensado en esa dirección, pretende ser un aporte para seguir analizando y discutiendo sobre esta forma de hacer historia que todavía tiene mucho por ofrecer y no es un hecho casual incluirlo en Folia Histórica del Nordeste, una de las revistas con mayor tradición en este campo en el país. 
